LIMA, M.A.C.; ALVES, R.E.; BISCEGLI, C.I.; FILGUEIRAS, H.A.C. Qualidade pós-colheita de melão Galia submetido à modificação da atmosfera e 1metilciclopropeno. Horticultura Brasileira, Brasília, v.23, n.3, p.793-798, jul-set 2005.

\title{
Qualidade pós-colheita de melão Galia submetido à modificação da atmosfera e ao 1-metilciclopropeno
}

\author{
Maria Auxiliadora C. de Lima ${ }^{1}$; Ricardo E. Alves ${ }^{2}$; Clóvis Isberto Biscegli³; Heloisa A.C. Filgueiras ${ }^{2}$

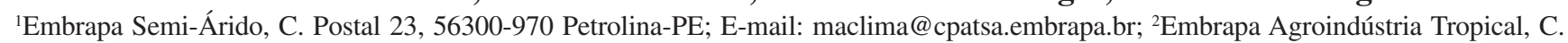 \\ Postal 3761, 60511-110 Fortaleza-CE; E-mail: elesbao@cnpat.embrapa.br; heloisa@cnpat.embrapa.br; ${ }^{3}$ Embrapa Instrumentação \\ Agropecuária, C. Postal 741, 13560-970 São Carlos-SP; E-mail: clovis@ cnpdia.embrapa.br
}

\section{RESUMO}

Avaliou-se o amaciamento da polpa, a formação da região de abscisão do pedúnculo, o comportamento respiratório, a produção de etileno e a qualidade de melão Galia 'Solar King' sob influência de atmosfera modificada (AM) e 1-metilciclopropeno (1-MCP), durante o armazenamento a $7,6 \pm 1,1^{\circ} \mathrm{C}$ e $87,6 \pm 6,3 \%$ UR seguido de temperatura ambiente $\left(24,2 \pm 0,7^{\circ} \mathrm{C}\right.$ e $88,1 \pm 5,4 \%$ UR). Os frutos, provenientes do Polo Agrícola Mossoró-Assu (RN), foram submetidos a tratamentos pós-colheita [controle, AM $\left(X-\right.$ Tend $\left.^{T M}\right)$, aplicação de 1-MCP (300 $\left.\mathrm{nl} \mathrm{L}^{-1}\right)$ e AM $\left(X-\right.$ Tend $\left.^{T M}\right)$ seguida da aplicação de 1$\left.\operatorname{MCP}\left(300 \mathrm{nl} \mathrm{L}^{-1}\right)\right]$ e a tempos de armazenamento $(0,7,14,21,24,27$ e 30 dias). O delineamento experimental foi inteiramente casualizado, em fatorial $4 \times 7$, com quatro repetições. Aos 23 dias, a atividade respiratória dos frutos tratados com 1-MCP foi menor que a dos demais, mantendo-se praticamente estável a partir do $25^{\circ}$ dia. Os tratamentos AM ou 1-MCP resultaram em picos de produção de etileno menores e precoces. Nos frutos sob AM, tratados ou não com 1$\mathrm{MCP}$, a perda de peso foi menor. Porém, a associação $\mathrm{AM}+1-\mathrm{MCP}$ foi mais vantajosa porque resultou em frutos mais firmes. $\mathrm{O}$ efeito mais evidente da aplicação de 1-MCP foi no atraso da evolução da abscisão do pedúnculo. A melhor aparência interna foi observada nos frutos tratados com 1-MCP e sob AM+1-MCP. Portanto, esta associação permitiu a melhor preservação da qualidade dos melões.

Palavras-chave: Cucumis melo var cantaloupensis, abscisão peduncular, comportamento respiratório, firmeza, tomografia de ressonância magnética.

\begin{abstract}
Postharvest quality of Galia muskmelon submitted to atmosphere modification and to 1-methylcyclopropene

The pulp softening, development of stalk abscission layer, respiratory behavior, ethylene production and postharvest quality of Galia 'Solar King' muskmelon were evaluated when submitted to modified atmosphere (MA) and 1-methylcyclopropene (1-MCP) during storage at $7.6 \pm 1.1^{\circ} \mathrm{C}$ and $87.6 \pm 6.3 \% \mathrm{RH}$ followed by ambient temperature $\left(24.2 \pm 0.7^{\circ} \mathrm{C}\right.$ and $\left.88.1 \pm 5.4 \% \mathrm{RH}\right)$. Fruits from Mossoró-Assu Region, Rio Grande do Norte State, Brazil, were submitted to postharvest treatments [control, MA $\left(X-\right.$ Tend $\left.^{T M}\right), 1-\mathrm{MCP}$ $\left(300 \mathrm{nl} \mathrm{L}^{-1}\right)$ and MA $\left(X-\right.$ Tend $\left.^{T M}\right)$ followed by 1-MCP $\left(300 \mathrm{nl} \mathrm{L}^{-1}\right)$ ] and storage periods $(0,7,14,21,24,27$ and 30 days). The experimental design was completely randomized, in a $4 \times 7$ factorial arrangement with four replications. At 23 days, the respiratory activity of fruits treated with 1-MCP was lower than the others, keeping the values almost steady from the $25^{\text {th }}$ to the $30^{\text {th }}$ day. The treatments with MA or 1-MCP resulted in lower and anticipated peaks of ethylene production. Fruits under MA, treated or not with 1-MCP, presented reduced weight lost. The association MA+1-MCP presented more advantages with firmer fruits. The most pronounced effect of 1-MCP application was a delay on the stalk abscission layer. The best internal appearance was observed on fruits treated with 1MCP or under MA+1-MCP application. This association permitted a better preservation of the quality of muskmelons.
\end{abstract}

Keywords: Cucumis melo var cantaloupensis, stalk abscission layer, respiratory behavior, firmness, magnetic ressonance image.

(Recebido para publicação em 8 de setembro de 2004 e aceito em 3 de junho de 2005)

A produção brasileira de melão está concentrada na Região Nordeste, especialmente nos estados do RN e CE, que respondem por $90 \%$ da produção nacional, numa área aproximada de 6.022 ha (AGRIANUAL, 2004).

Entre os grupos de melão produzidos e comercializados mundialmente, o Galia pertence àqueles denominados nobres. No Brasil, o seu cultivo foi introduzido por volta de 1995 para suprir o mercado europeu na entressafra dos concorrentes, principalmente Espanha e Israel (MENEZES et al., 1998). Atualmente, é um dos mais cultivados na região de Mossoró-Assu (RN), principal agropolo brasileiro produtor de melão.

Alguns fatores têm fortalecido a idéia de que a exportação de melão Galia só é possível com a utilização de técnicas de conservação pós-colheita eficientes. A afirmativa é baseada na sua limitada vida útil (14 dias), sob temperatura ambiente (LESTER; STEIN, 1993).

A refrigeração é a técnica mais difundida na cadeia de comercialização de frutas e hortaliças mas quando usada isoladamente não mantém a qualidade de alguns produtos por tempo compatível com as necessidades de mercado. $\mathrm{O}$ uso conjunto com outras técnicas, como atmosfera modificada (AM) e inibidores de etileno, pode aumentar a vida útil do produto, mantendo a qualidade por mais tempo (KLUGE et al., 1999; ARGENTA et al., 2001). O emprego de AM, utilizando-se de filmes poliméricos, tem contribuído para estender a vida útil e manter a qualidade de frutos e hortaliças (KADER, 1995). Os benefícios dessa técnica advêm da redução da atividade metabólica do produto, que é conseqüência dos níveis baixos de $\mathrm{O}_{2}$ e elevados de $\mathrm{CO}_{2}$ existentes no interior da embalagem.

Inibidores da ação do etileno, como o 1-metilciclopropeno (1-MCP), também têm sido estudados para retardar o 
amadurecimento (ARGENTA et al., 2001; DONG et al., 2002). O 1-MCP é um composto gasoso que compete com o etileno pelos sítios de ligação com receptores nas membranas celulares (SISLER; SEREK, 1997) e, por esta razão, tem sido avaliado com o propósito de retardar o amadurecimento de frutos (FAN et al., 2000; WATKINS et al., 2000; DONG et al., 2002), o que pode favorecer a exploração de mercados mais distantes e permitir maior elasticidade para oferta dos produtos. Tais benefícios poderiam ampliar as chances de exportação de melões como o Galia, bastante aceitos pelo mercado europeu.

Estudos realizados por Lima et al. (2004) demonstraram que a aplicação de 1-MCP atrasa o amaciamento da polpa e a evolução da abscisão do pedúnculo, em melão Galia 'Solar King' armazenado sob temperatura ambiente. Segundo os autores, esses efeitos foram igualmente observados com o emprego de $300 \mathrm{nl} \mathrm{L}^{-1}$ e $900 \mathrm{nl} \mathrm{L}{ }^{-1}$ de 1-MCP, sendo que a primeira dose foi a recomendada economicamente.

Neste estudo avaliou-se o amaciamento da polpa, a formação da região de abscisão do pedúnculo, o comportamento respiratório, a produção de etileno e a qualidade pós-colheita de melão Galia 'Solar King' sob influência de AM e/ou 1-MCP.

\section{MATERIAL E MÉTODOS}

Foram utilizados melões Galia 'Solar King' oriundos de plantio em Mossoró. Os frutos foram colhidos quando a região em torno do pedúnculo ainda apresentava-se sem sinais de rachadura, seguindo critérios para exportação para o mercado europeu. Em seguida, receberam aplicação de uma solução contendo o fungicida Imazalil e a cera Megh $\mathrm{Wax}^{\mathrm{TM}}$, ambos na concentração de $2 \mathrm{ml}$ $\mathrm{L}^{-1}$, ao redor do pedúnculo. Posteriormente, foram transportados para o laboratório da Embrapa Agroindústria Tropical, em Fortaleza (CE).

Após seleção para descarte de frutos que exibissem danos decorrentes do transporte, eles foram submetidos a tempos de armazenamento $(0,7,14,21,24$, 27 e 30 dias) e tratamentos pós-colheita que compreenderam: 1) controle (fru- tos armazenados sem embalagem e sem exposição ao 1-MCP); 2) uso de AM, através do filme de polietileno de baixa densidade $\left(\mathrm{X}-\mathrm{Tend}^{\mathrm{TM}}\right)$, recomendado pelo fabricante para o melão Galia durante o armazenamento a temperaturas de 7 a $\left.10^{\circ} \mathrm{C} ; 3\right)$ aplicação de $1-\mathrm{MCP}(300$ $\left.\mathrm{nl} \mathrm{L} \mathrm{L}^{-1}\right)$ e 4) aplicação de 1-MCP (300 nl $\mathrm{L}^{-1}$ ) em frutos previamente embalados para obtenção da AM (X-Tend $\left.{ }^{\mathrm{TM}}\right)$. Todos os frutos foram armazenados sob refrigeração por até 21 dias $\left(7,6 \pm 1,1^{\circ} \mathrm{C}\right.$ e $87,6 \pm 6,3 \%$ UR) e, em seguida, transferidos para temperatura ambiente $\left(24,2 \pm 0,7^{\circ} \mathrm{C}\right.$ e $88,1 \pm 5,4 \%$ UR $)$.

Os tratamentos com 1-MCP foram realizados em câmaras herméticas com capacidade para $0,186 \mathrm{~m}^{3}$, onde o gás foi liberado após dissolução em água a $50^{\circ} \mathrm{C}$. Os frutos foram mantidos expostos ao 1-MCP por 12 horas, sob temperatura aproximada de $25^{\circ} \mathrm{C}$. Após esse período, foram armazenados nas condições de temperatura e umidade relativa descritas anteriormente.

Foram avaliadas as variáveis: (a) Atividade respiratória $\left(\mathrm{mg} \mathrm{CO}_{2} \mathrm{~kg}^{-1} \mathrm{~h}^{-1}\right)$, determinada em cromatógrafo a gás $\mathrm{CG}$ modelo DANI 86.10 através de detector de condutividade térmica $\left(150^{\circ} \mathrm{C}\right)$, em coluna PORAPAK-N (4 m x 3,2 mm); (b) Produção de etileno $\left(\mathrm{ml} \mathrm{C}_{2} \mathrm{H}_{4} \mathrm{~kg}^{-1} \mathrm{~h}^{-1}\right)$, determinada em cromatógrafo a gás $\mathrm{CG}$ modelo DANI 86.10 utilizando-se detector de ionização de chama $\left(200^{\circ} \mathrm{C}\right)$; (c) Perda de peso (\%), obtida pela diferença entre o peso individual do fruto no dia da colheita e na data da avaliação, utilizando balança semi-analítica; (d) Firmeza da polpa (N), determinada como a resistência da polpa à penetração, utilizando penetrômetro manual modelo FT 327, com ponteira de $8 \mathrm{~mm}$ de diâmetro; (e) Abscisão do pedúnculo, através de escala subjetiva de 4 a 0 , avaliada por três julgadores, adotando-se 4= ausência de rachadura em torno do pedúnculo, $3=$ presença em menos de $25 \%$ do perímetro em torno do pedúnculo, $2=$ presença em mais de $25 \%$ e menos de $50 \%$ do perímetro, $1=$ presença em mais de $50 \%$ e menos de $75 \%$ do perímetro e $0=$ abscisão de mais de 75\% do pedúnculo; (f) Acidez total titulável (ATT, \% de ácido cítrico), determinada por titulação com solução de $\mathrm{NaOH}$ 0,1 M; (g) Sólidos solúveis to- tais (SST,\%), determinados por leitura em refratômetro digital ATAGO PR 101, escala de 0 a $45 \%$, com compensação automática de temperatura; (h) Aparência externa, avaliada por três julgadores, através de escala subjetiva de 5 a 0 , em que 5= ausência de depressões, manchas ou ataque de microrganismos, $4=$ traços de depressões e/ou manchas, $3=$ depressões e/ou manchas leves, $2=$ depressões e/ou manchas com média intensidade, $1=$ depressões e/ou manchas com intensidade severa ou ataque de microrganismos e $0=$ depressões e/ou manchas com intensidade muito severa ou ataque generalizado de microrganismos; (i) Aparência interna, avaliada por três julgadores, utilizando escala subjetiva de 5 a 0 , em que 5= ausência de colapso na polpa e/ ou sementes soltas e/ou líquido na cavidade, $4=$ traços de colapso na polpa e/ou sementes soltas e/ou líquido na cavidade, $3=$ colapso na polpa e/ou sementes soltas e/ou líquido na cavidade com intensidade leve, $2=$ colapso na polpa e/ou sementes soltas e/ou líquido na cavidade com média intensidade, $1=$ colapso na polpa e/ou sementes soltas e/ou líquido na cavidade com intensidade severa e $0=$ colapso na polpa e/ou sementes soltas e/ ou líquido na cavidade com intensidade muito severa.

O amaciamento da polpa foi acompanhado por imagens de tomografia de ressonância magnética (RM), realizada aos 21 e 24 dias após a colheita, em frutos previamente separados para este fim. Para a obtenção das imagens, os frutos foram acondicionados e transportados via aérea até a Embrapa Instrumentação Agropecuária, em São Carlos (SP). Por esta razão, as datas das imagens não coincidiram com as demais avaliações.

As imagens foram obtidas em tomógrafo de ressonância magnética nuclear (Varian Inova de 2 Tesla), dispondo de uma bobina de radiofrequiência do tipo gaiola com diâmetro interno de $14 \mathrm{~cm}$ e operando na frequiência de 85,53 MHz. O princípio de obtenção das imagens baseia-se na detecção dos prótons de hidrogênio $\left(\mathrm{H}^{+}\right)$, presentes essencialmente nas moléculas de água. As imagens bidimensionais foram geradas em matrizes de 256 x 256 pixels, em 256 tons de cinza, em fatias de $2 \mathrm{~mm}$ de espessura e analisadas com relação à lo- 
calização e textura dos graus de cinza. Estes indicam o estado da água na polpa do fruto: mais móvel (livre) ou mais ligada aos tecidos.

O delineamento experimental foi inteiramente casualizado, em fatorial 4x7 (tratamentos pós-colheita $\mathrm{x}$ tempo de armazenamento), com quatro repetições compostas por um fruto cada. As taxas de atividade respiratória e produção de etileno foram avaliadas a intervalos menores que as demais variáveis a fim de se caracterizar melhor o padrão respiratório dos frutos. As referidas variáveis não apresentaram homocedasticidade das variâncias, conforme teste de Bartlett, não sendo, portanto, submetidas à análise de variância. Optou-se, em ambos os casos, por apresentar as médias referentes a cada tratamento pós-colheita em cada tempo.

Para as demais variáveis, procedeuse às análises de variância. Nos casos em que o efeito do tempo de armazenamento foi significativo, os dados foram submetidos à análise de regressão polinomial. Para avaliar as diferenças entre as médias dos tratamentos pós-colheita, utilizou-se o teste de Tukey a 5\% de probabilidade. Finalmente, quando houve efeito significativo da interação entre os fatores, realizou-se o desdobramento dos tratamentos póscolheita em cada tempo de armazenamento através de análise de regressão polinomial.

\section{RESULTADOS E DISCUSSÃO}

Durante o armazenamento refrigerado, a atividade respiratória dos frutos controle e dos tratados com 1-MCP mantiveram-se em níveis equivalentes, próximos a $15 \mathrm{mg} \mathrm{CO} \mathrm{kg}^{-1} \mathrm{~h}^{-1}$ (Figura 1A). Após a transferência para a temperatura ambiente, a atividade respiratória aumentou expressivamente, sendo mais baixa, até o $23^{\circ}$ dia, nos frutos que receberam 1-MCP. Para os tratamentos AM e controle, as diferenças desde o $21^{\circ}$ até o $23^{\circ}$ dia, não foram representativas. Por sua vez, ao $23^{\circ}$ dia, a associação $\mathrm{AM}+1-\mathrm{MCP}$ resultou em resposta intermediária em relação aos demais tratamentos. A partir do $25^{\circ}$ dia, a atividade respiratória dos frutos tratados apenas com 1-MCP manteve-se praticamente


Figura 1. Atividade respiratória (A) e produção de etileno (B) de melão Galia 'Solar King' submetido a atmosfera modificada (AM) e/ou a aplicação de 1-MCP, durante 21 dias de armazenamento refrigerado $\left(7,6 \pm 1,1^{\circ} \mathrm{C}\right.$ e $87,6 \pm 6,3 \%$ UR) seguido de 9 dias em temperatura ambiente $\left(24,2 \pm 0,7^{\circ} \mathrm{C}\right.$ e $88,1 \pm 5,4 \%$ UR). Embrapa, 2004.

*As barras verticais indicam os desvios padrões. A seta representa a data da retirada dos frutos da refrigeração.

estável, até o final do armazenamento.

Em estudos realizados com melão Cantaloupe 'Hy-Mark', Almeida (2002) observou que a aplicação de $300 \mathrm{nl} \mathrm{L}^{-1}$ de 1-MCP reduziu a atividade respiratória durante o armazenamento. Segundo Golding et al. (1998), a redução na atividade respiratória promovida pelo 1 MCP pode resultar de um efeito no metabolismo dos carboidratos.

Os efeitos dos tratamentos pós-colheita sobre a produção de etileno foram melhor caracterizados nos primeiros dias após a transferência para temperatura ambiente (Figura 1B). Contu- do, os tratamentos AM e 1-MCP isoladamente resultaram em picos menores e mais precoces. Um segundo pico na produção de etileno foi observado nos frutos tratados com 1-MCP, podendo estar relacionado ao aparecimento de novos sítios receptores do fitormônio, conforme relatado por Pathak et al. (2003) em banana, o que indicaria uma possível perda de efetividade do tratamento aproximadamente aos 27 dias.

Estudos realizados com outros frutos têm demonstrado que tratamentos com 1MCP reduzem consideravelmente a atividade respiratória e atrasam o climatério 


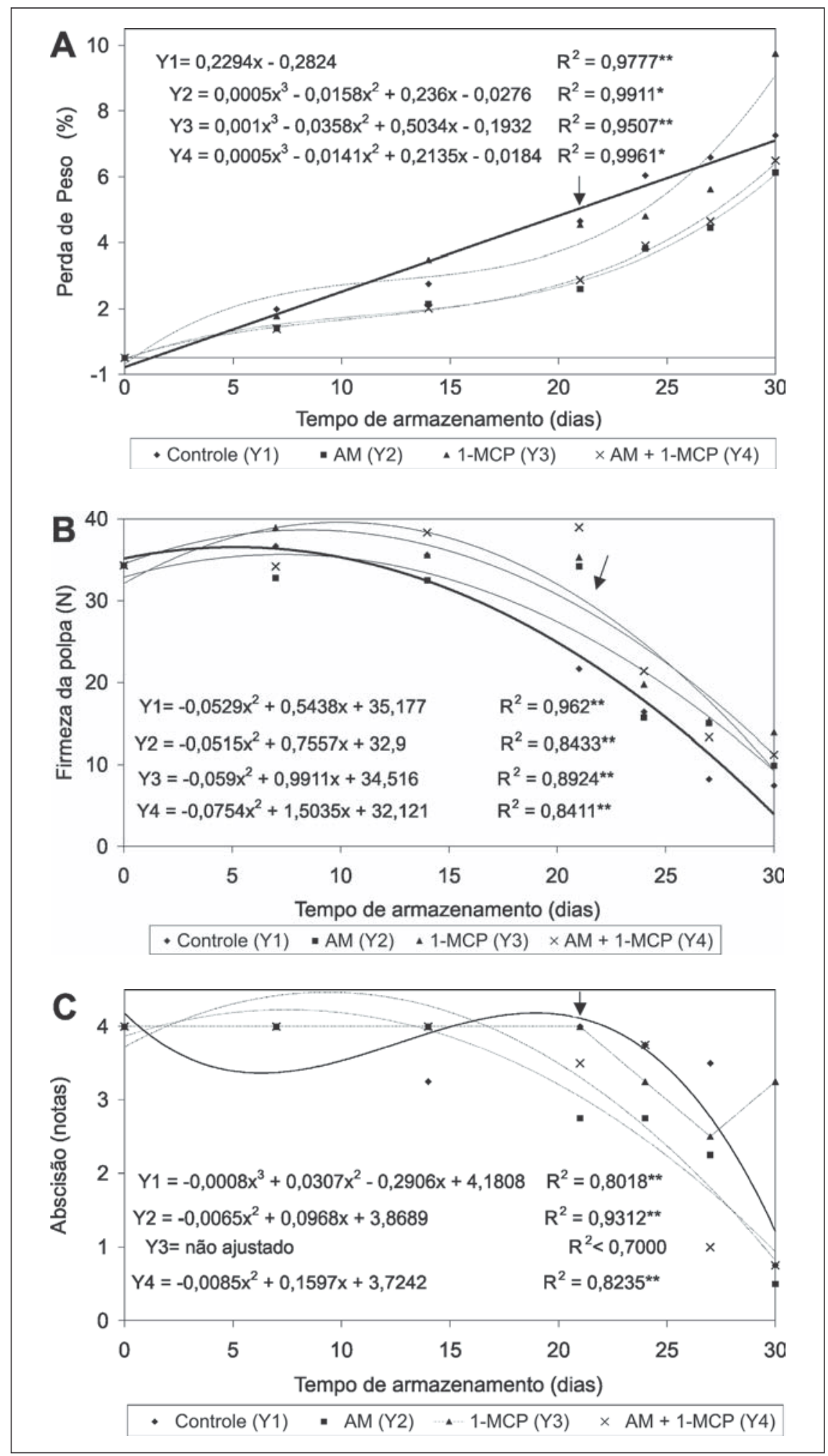

Figura 2. Perda de peso (A), firmeza da polpa (B) e abscisão do pedúnculo (C) de melão Galia 'Solar King' submetido a atmosfera modificada (AM) e/ou aplicação de 1-MCP, durante 21 dias de armazenamento refrigerado $\left(7,6 \pm 1,1^{\circ} \mathrm{C}\right.$ e $87,6 \pm 6,3 \%$ UR) seguido de 9 dias em temperatura ambiente $\left(24,2 \pm 0,7^{\circ} \mathrm{C}\right.$ e $88,1 \pm 5,4 \%$ UR). A seta representa a data da retirada dos frutos da refrigeração. Embrapa, 2004.

(GOLDING et al., 1998; ARGENTA et al., 2001; DONG et al., 2002). Esse efeito é indicativo de atividade metabólica re- duzida e, consequentemente, da possibilidade de menor produção de substratos (GOLDING et al., 1998).
A perda de peso aumentou em todos os tratamentos (Figura 2A). Porém, a partir do $27^{\circ}$ dia, a perda foi maior nos frutos tratados apenas com 1-MCP. A AM por si só foi eficiente em diminuir a perda de água, especialmente quando os frutos foram mantidos sob refrigeração. Aos 21 dias de armazenamento, a perda de peso observada nos tratamentos $\mathrm{AM}$ e $\mathrm{AM}+1 \mathrm{MCP}$ foi praticamente a metade daquela verificada no controle. Esta resposta é um dos principais benefícios do uso da AM (KADER, 1995) e resulta da reduzida taxa de permeabilidade ao vapor d'água característica do filme polimérico utilizado.

Observou-se retenção da firmeza nos frutos tratados, notadamente os submetidos a 1-MCP e AM+1-MCP (Figura 2B). Nestes, os valores foram bastante próximos durante todo o experimento, sugerindo o 1-MCP como promotor da resposta. Outros autores já observaram frutos mais firmes após a aplicação de 1-MCP (ARGENTA et al., 2001; DONG et al., 2002; JEONG et al., 2002). Mas vale considerar que a magnitude do efeito depende da concentração de 1-MCP aplicada e do estádio de maturação do fruto (PELAYO et al., 2003).

$\mathrm{O}$ atraso no amaciamento resultante da ação do 1-MCP é coerente com a hipótese de que é o etileno que desencadeia a atividade metabólica relacionada ao processo (JEONG et al., 2002). O uso de AM também tem se mostrado efetivo na redução da perda de firmeza de frutos armazenados, tendo sido relatada em estudos realizados por Rodov et al. (2000) e Hertog et al. (2001).

A resposta obtida na avaliação da firmeza da polpa através de penetrômetro foi confirmada pelas imagens de tomografia de RM. Aos 24 dias após a colheita, a polpa dos frutos tratados com 1-MCP e AM+1-MCP mostrava-se firme e não suculenta. As tonalidades de cinza mais escuro próximo à casca mostram regiões mais imaturas. Por sua vez, os frutos controle e aqueles submetidos a AM exibiam polpa suculenta com sementes praticamente soltas e maior presença de água livre (regiões mais claras). Aos 21 dias, a presença de líquido na polpa (cores mais claras na imagem) e de sementes praticamente soltas era maior do que a ob- 
servada aos 24 dias, em especial nos frutos controle. Nessa data, os frutos submetidos a AM e AM+1-MCP apresentavam-se com polpa firme e uniforme. Estas diferenças, aparentemente contraditórias em relação ao número de dias após a colheita, são explicadas pelo intervalo de tempo entre o transporte dos frutos e a obtenção das imagens. Para o primeiro grupo de amostras (21 dias), esse período foi de sete dias, sob temperatura ambiente, enquanto na segunda data, esse intervalo foi de três dias.

A abertura na região do pedúnculo começou a se desenvolver praticamente após a transferência dos frutos para temperatura ambiente (Figura 2C). Ao final do período de armazenamento, os frutos tratados com 1-MCP exibiam menos abscisão do pedúnculo (inferior a $50 \%$ ) e, portanto, estavam menos propensos a infecção através desta região.

Segundo Ayub et al. (1996), eventos do amadurecimento do melão como amaciamento da polpa e ativação da abscisão peduncular são dependentes de etileno, explicando a evolução mais lenta desses processos nos frutos tratados com 1-MCP, como também observado por Ianetta et al. (2000). Estes autores consideram que o 1-MCP reduz significativamente a atividade enzimática de degradação na região de abscisão dos frutos de Rubus idaeus através do bloqueio da formação da endo-b-1,4glucanase e da redução do seu acúmulo nos receptáculos.

Não houve variações significativas no teor de SST durante o período avaliado e nem influência dos tratamentos com AM e/ou de 1-MCP (dados não apresentados). Os valores médios variaram de 9,5 a $10,7 \%$.

Por outro lado, a ATT exibiu tendência de leve aumento, sendo um pouco menos acentuado nos frutos sob AM. Uma vez que as diferenças foram muito pequenas (no máximo 0,02 unidades percentuais de ácido cítrico), os dados não foram apresentados.

Esta é uma resposta comum em melão. De modo geral, as variações nos principais componentes químicos após a colheita são pouco significativas (MENEZES et al., 1998) e, portanto, não podem contribuir para diferenças facilmente detectáveis no sabor. Os autores
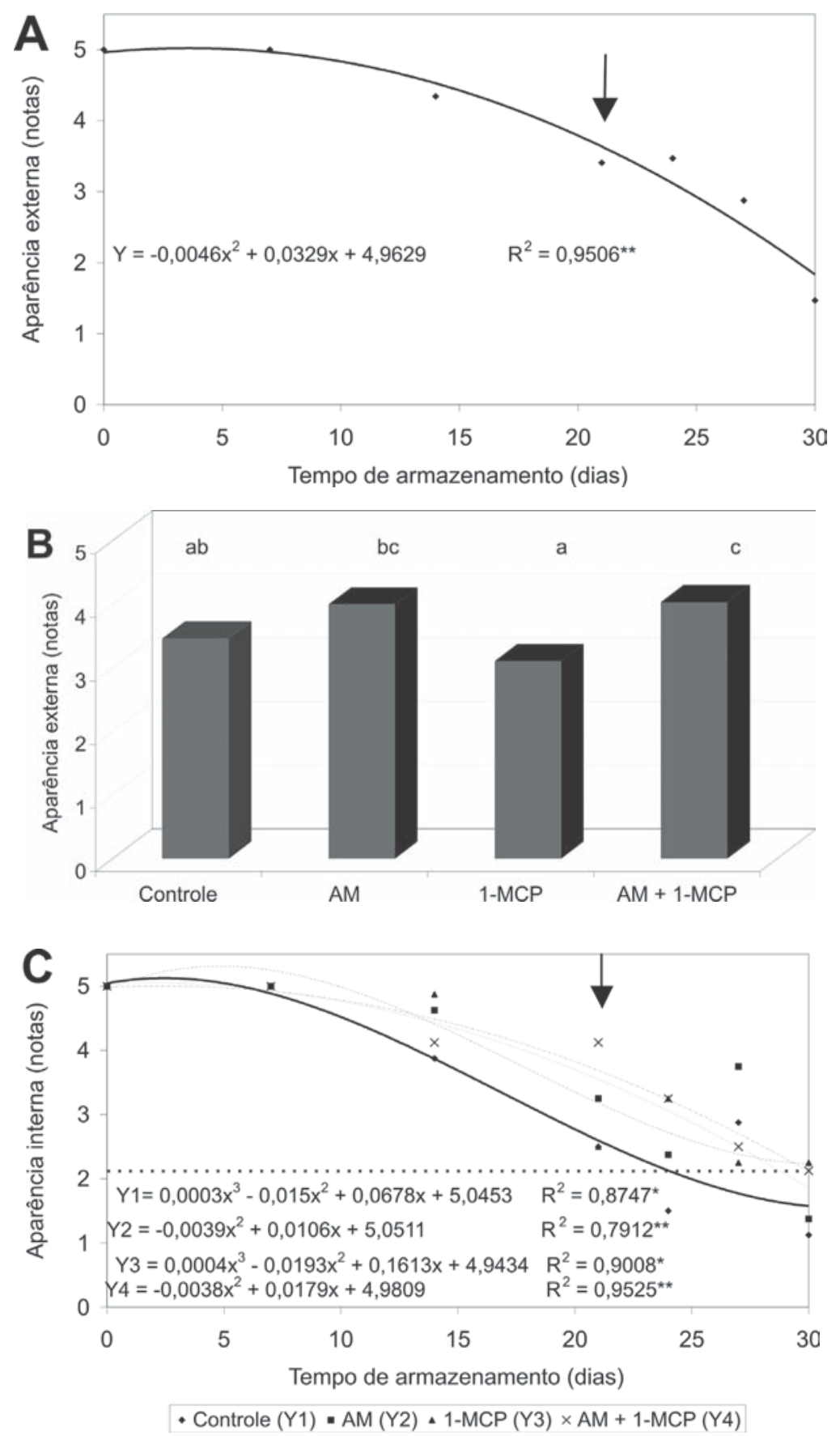

Figura 3. Aparência externa (A e B) e interna (C) de melão Galia 'Solar King' submetido a atmosfera modificada (AM) e/ou a aplicação de 1-MCP, durante 21 dias de armazenamento refrigerado $\left(7,6 \pm 1,1^{\circ} \mathrm{C}\right.$ e $87,6 \pm 6,3 \%$ UR) seguido de 9 dias em temperatura ambiente $\left(24,2 \pm 0,7^{\circ} \mathrm{C}\right.$ e $88,1 \pm 5,4 \%$ UR). Embrapa, 2004.

A representa os valores médios dos tratamentos pós-colheita; B representa os valores médios dos tempos de armazenamento. A linha paralela ao eixo x indica o limite de aceitação dos frutos pelo consumidor e a seta representa a data em que foram retirados da refrigeração. Notas da aparência externa: $5=$ ausência de depressões, manchas ou ataque de microrganismos, $4=$ traços de depressões e/ou manchas, 3 = depressões e/ou manchas leves, 2 = depressões e/ou manchas com média intensidade, 1= depressões e/ou manchas com intensidade severa ou ataque de microrganismos e $0=$ depressões e/ou manchas com intensidade muito severa ou ataque generalizado de microrganismos. Notas da aparência interna: $5=$ ausência de colapso na polpa e/ou sementes soltas e/ou líquido na cavidade, $4=$ traços de colapso na polpa e/ou sementes soltas e/ou líquido na cavidade, $3=$ colapso na polpa e/ou sementes soltas e/ou líquido na cavidade com intensidade leve, $2=$ colapso na polpa e/ou sementes soltas e/ou líquido na cavidade com média intensidade, $1=$ colapso na polpa e/ou sementes soltas e/ou líquido na cavidade com intensidade severa e $0=$ colapso na polpa e/ou sementes soltas e/ou líquido na cavidade com intensidade muito severa. 
destacaram, inclusive, que a ATT, assim como o pH, não é bom indicador para avaliação da qualidade de melão após a colheita.

A aparência é decisiva para definir a qualidade do fruto. Neste estudo, a aparência externa foi afetada isoladamente pelo tempo de armazenamento e pelos tratamentos pós-colheita (Figuras 3A e 3B). Os melões mantiveram-se adequados para comercialização até o $27^{\circ}$ dia. A partir daí, verificou-se que as notas médias foram inferiores a 2,0, limitando a aceitação dos frutos pelos consumidor (Figura 3A).

$\mathrm{O}$ emprego de $\mathrm{AM}+1-\mathrm{MCP}$ resultou em frutos de melhor aparência externa. Da mesma forma, a aparência interna desses frutos foi melhor apesar das diferenças entre os tratamentos AM e 1$\mathrm{MCP}$ isoladamente terem sido pouco perceptíveis (Figura 3C). No entanto, todos se diferenciaram do controle, que teve vida útil limitada pela aparência interna já aos 24 dias.

Nas condições deste estudo, a aplicação de 1-MCP (300 nl L-1) associada ao emprego de AM com o filme polimérico $X$-Tend ${ }^{T M}$ promoveu maiores benefícios à qualidade do melão Galia 'Solar King' durante o armazenamento. A combinação resultou na associação dos efeitos individuais de cada técnica, obtendo-se frutos com menor perda de massa, mais firmes e de melhor aparência.

\section{AGRADECIMENTOS}

Ao CNPq e à FUNCAP, pela concessão de Bolsa de Estudos, à Empresa AgroFresh Inc. (subsidiária da Rohm and Haas Química Ltda), pelo apoio financeiro, e à NOLEM Comercial Importadora e Exportadora Ltda, pela concessão dos frutos.

\section{LITERATURA CITADA}

AGRIANUAL 2004. Anuário da Agricultura Brasileira. FNP Consultoria \& AgroInformativos: São Paulo, 2004, 496 p.

ALMEIDA, A.S. Conservação de melão Cantaloupe 'Hy-Mark' tratado com 1metilciclopropeno após a colheita. 2002. $143 \mathrm{f}$. Dissertação (Mestrado em Fisiologia pós-colheita) - Escola Superior de Agricultura de Mosoró, Mossoró.

ARGENTA, L.C.; MATTHEIS, J.; FAN, X. Retardamento da maturação de maçãs 'Fuji' pelo tratamento com 1-MCP e manejo da temperatura. Revista Brasileira de Fruticultura, v.23, n.2, p.270-273. 2001.

AYUB, R.; GUIS, M.; BEN AMOR, M.; GILLOT, L.; ROUSTAN, J.P.; LATCHÉ, A.; BOUZAYEN, M.; PECH, J.C. Expression of ACC oxidase antisense gene inhibits ripening of cantaloupe melon fruits. Nature Biotechnology, v.14, p.862866, 1996.

DONG, L.; LURIE, S.; ZHOU, H.W. Effect of 1methylcyclopropene on ripening of 'Canino' apricots and 'Royal Zee' plums. Postharvest Biology and Technology, v.24, n.2, p.135-145, 2002

FAN, X.; ARGENTA, L.; MATTHEIS, J.P. Inhibition of ethylene action by 1methylcyclopropene prolongs storage life of apricots. Postharvest Biology and Technology, v.20, n.2, p.135-142, 2000.

GOLDING, J.B.; SHEARER, D.; WYLLIE, S.G.; McGLASSON, W.B. Application of 1-MCP and propylene to identify ethylene-dependent ripening processes in mature banana fruit. Postharvest Biology and Technology, v.14, n.1, p.87-98, 1998. HERTOG, M.L.A.T.M.; NICHOLSON, S.E.; BANKS, N.H. The effect of modified atmosphere on the rate of firmness change in 'Braeburn' apple. Postharvest Biology and Technology, v.23, n.2, p.175-184, 2001.

IANNETTA, P.P.M.; WYMAN, M.; NEELAM, A.; TAYLOR, M.A.; DAVIES, H.V.; SEXTON, R. A causal role for ethylene and endo-b-1,4glucanase in the abscission of red-raspberry (Rubus idaeus) drupelets. Physiologia Plantarum, v.110, p.535-543, 2000.

JEONG, J.; HUBER, D.J.; SARGENT, S.A. Influence of 1-methylcyclopropene (1-MCP) on ripening and cell-wall matrix polysaccharides of avocado (Persea americana) fruit. Postharvest Biology and Technology, v.25, n.3, p.241-256, 2002.
KADER, A.A. Regulation on fruit physiology by controlled/modified atmospheres. Acta Horticulturae, n.398, p.81-91, 1995.

KLUGE, R.A.; BILHALVA, A.B.; CANTILLANO, R.F.F. Influência do estádio de maturação e da embalagem de polietileno na frigoconservação de ameixa. Pesquisa Agropecuária Brasileira, Brasília, v.34, n.3, p.323329, 1999.

LESTER, G.E.; STEIN, E. Plasma membrane physicochemical changes during maturation and postharvest storage of muskmelon fruit. Journal of the American Society for Horticultyura Science, v.118, n.2, p.223-227,1993.

LIMA, M.A.C.; ALVES, R.E.; BISCEGLI, C.I.; FILGUEIRAS, H.A.C.; COCOZZA, F.M. Conservação pós-colheita de melões Galia 'Solar King' tratados com 1-metilciclopropeno. Horticultura Brasileira, Brasília, v.22, n.1, p.121126, 2004.

MENEZES, J.B.; CHITARRA, A.B.; CHITARRA, M.I.F.; BICALHO, U.O. Caracterização do melão tipo Galia durante o armazenamento. Horticultura Brasileira, Brasília, v.16, n.2, p.159-164, 1998.

PATHAK, N.; ASIF, M.H.; DHAWAN, P.; SRIVASTAVA, M.K.; NATH, P. Expression and activities of ethylene biosynthesis enzymes during ripening of banana fruits and effect of 1-MCP treatment. Plant Growth Regulation, v.40, n.1, p.11-19, 2003.

PELAYO, C.; VILAS-BOAS, E.V.B.; BENICHOU, M.; KADER, A.A. Variability in responses of partially ripe bananas at 1methylcyclopropene. Postarvest Biology and Tecnology, v.28, n.1, p.75-85, 2003.

RODOV, V.; AGAR, T.; PERETZ, J.; NAFUSSI, B.; KIM, J.J.; BEN-YEHOSHUA, S. Effect of combined application of heat treatments and plastic packaging on keeping quality of 'Oroblanco' fruit (Citrus grandis L.x C. paradisi Macf.). Postharvest Biology and Technology, v.20, n.3, p.287-294, 2000.

SISLER, E.C.; SEREK, M. Inhibitors of ethylene responses in plants at the receptor level: recent developments. Physiologia Plantarum, v.100, p.577-582, 1997.

WATKINS, C.B.; NOCK, J.F.; WHITAKER, B.D. Responses of early, mid and late season apple cultivars to postharvest application of 1methylcyclopropene (1-MCP) under air controlled atmosphere storage conditions. Postharvest Biology and Technology, v.19, n.1, p.17-32, 2000. 